\title{
Commentary
}

\section{Is rapamycin a rapalog?}

\author{
David J. Glass ${ }^{\mathrm{a}}$ and Dudley W. Lamming ${ }^{\mathrm{b}, *}$ \\ ${ }^{a}$ Novartis Institutes for Biomedical Research, Cambridge, MA, USA \\ ${ }^{\mathrm{b}}$ Department of Medicine, University of Wisconsin-Madison, Madison, WI, USA
}

\begin{abstract}
David Glass and Dudley Lamming debate the question of "Is Rapamycin a Rapalog" while the world votes.
\end{abstract}
Keywords: Rapamycin, RAD0001, everolimus, mTORC1, mTORC2, aging

\section{Introduction}

Rapamycin, a molecule purified from bacteria discovered on Easter Island in 1975, has over the last decade attracted significant attention for its ability to extend the lifespan of model organisms including mice, even if given transiently or intermittently [1-4]. Importantly, rapamycin may also be able to protect tissues from the ravages of age and potentially functionally rejuvenate some aged tissues; tissues benefiting from short-term rapamycin treatment include (in rodents) the heart [5], hematopoietic stem cells [6], and the kidney [7], and (in humans) the immune system [8]. Despite the significant potential benefits that rapamycin may offer as a therapy to slow, treat, or reverse age-related disease in humans, work has proceeded cautiously due to the fear of the side effects of rapamycin, which include immunosuppression, dermatological events and metabolic disruption. Many of these side effects result, in whole or in part, from the "off-target" effects of rapamycin on a protein kinase, the mechanistic Target of Rapamycin Complex 2 mTORC2 $[9,10]$.

There has been significant interest in developing compounds that avoid or mitigate the effects

\footnotetext{
*Corresponding author: Dudley W. Lamming, PhD, Assistant Professor of Medicine, University of Wisconsin-Madison, 2500 Overlook Terrace, VAH C3127 Research 151, Madison, WI 53705, USA. Tel.: +1 608256 1901/Ext. 12861; Fax: +1 608263 9983; E-mail: dlamming@medicine.wisc.edu.
}

of rapamycin by avoiding off-target inhibition of mTORC2 [9]. While the vast majority of work with rapamycin has utilized the original parent compound, short-term treatment with a rapamycin derivative - RAD0001 (Everolimus) - has shown potential benefits in humans [8], and Everolimus shows reduced, although still significant, metabolic side effects in mice [11]. Analogs of rapamycin have traditionally been called "rapalogs", which led one of us (DJG) to pose the question: is rapamycin a rapalog?

\section{Debate}

DJG: Debate question for the day: Does Rapamycin belong in a group of compounds labelled "Rapalogs"?

DWL: It is the founding member of the class.

DWL: I view it as asking if the USS Nimitz is a Nimitz-class carrier. The Navy thinks the founding vessel of each class of aircraft carrier, ship, submarine, etc. is a member of that class.

DJG: What is the definition of a rapalog? A rapalog is a "rapamycin analog," per the first use of the term in Pubmed [12]. Can a thing be an analog of itself? Put another way, is a chocolate chip cookie an analog of a chocolate chip cookie? No. 


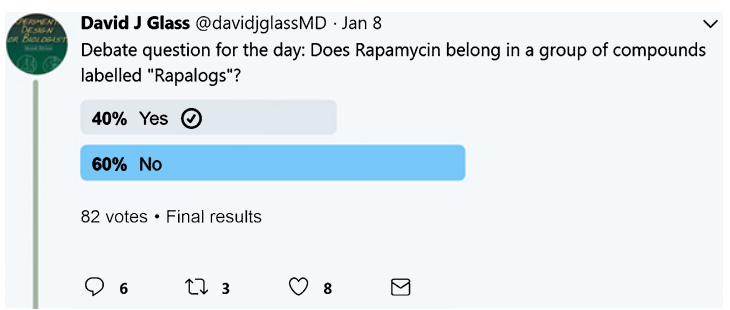

Fig. 1. Twitter poll on "Is Rapamycin a Rapalog?"

DWL: Hmm, Wikipedia says that rapalogs are "rapamycin and its inhibitors" [13].

DJG: I know, let's ask the internet! We will do a Twitter poll.

DJG: The people have spoken, and rapamycin is not a rapalog.

Noted mTOR expert Dr. David M. Sabatini [14]: (Arriving in a flash of light) DWL, you would been correct if it was a Nimitzlog-class carrier. (Vanishing in a puff of smoke)

DJG: Well, that is that folks. Although I always thought that the bit about saying rapamycin three times fast and having David Sabatini appear was a myth.

DWL: Nope, it's definitely true (at least on Twitter). I guess we will be stuck writing "Rapamcyin and the rapalogs" for the indefinite future.

In conclusion, rapamycin is not a rapalog. Unless, of course, one is referring a class of molecules that has rapamycin-like activity but is not confined to chemical derivatives of rapamycin (e.g. [15]); this debate is left for a separate occasion.

\section{Grant Information}

The authors declare that no grants were involved in supporting this work.

\section{Acknowledgments}

We thank Dr. David M. Sabatini for the use of his name, insight, and sense of humor. The above discussion is a dramatization of a discussion conducted on Twitter on January 8-9, 2018, https://twitter. com/davidjglassMD/status/950496850192338944.

\section{References}

[1] Arriola Apelo SI, Lamming DW. Rapamycin: An InhibiTOR of aging emerges from the soil of easter Island. J Gerontol A Biol Sci Med Sci. 2016;71(7):841-9.

[2] Arriola Apelo SI, Pumper CP, Baar EL, Cummings NE, Lamming DW. Intermittent administration of rapamycin extends the life span of female C57BL/6J mice. J Gerontol A Biol Sci Med Sci. 2016;71(7):876-81.

[3] Miller RA, Harrison DE, Astle CM, Fernandez E, Flurkey K, Han M, et al. Rapamycin-mediated lifespan increase in mice is dose and sex dependent and metabolically distinct from dietary restriction. Aging Cell. 2014;13(3):468-77.

[4] Bitto A, Ito TK, Pineda VV, LeTexier NJ, Huang HZ, Sutlief E, et al. Transient rapamycin treatment can increase lifespan and healthspan in middle-aged mice. eLife. 2016;5.

[5] Ramos FJ, Chen SC, Garelick MG, Dai DF, Liao CY, Schreiber KH, et al. Rapamycin reverses elevated mTORC1 signaling in lamin A/C-deficient mice, rescues cardiac and skeletal muscle function, and extends survival. Sci Transl Med. 2012;4(144):144ra03.

[6] Chen C, Liu Y, Liu Y, Zheng P. mTOR regulation and therapeutic rejuvenation of aging hematopoietic stem cells. Sci Signal. 2009;2(98):ra75.

[7] Shavlakadze T, Zhu J, Wang S, Zhou W, Morin B, Egerman MA, et al. Short-term low-dose mTORC1 inhibition in aged rats counter-regulates age-related gene changes and blocks age-related kidney pathology. J Gerontol A Biol Sci Med Sci. 2018.

[8] Mannick JB, Del Giudice G, Lattanzi M, Valiante NM, Praestgaard J, Huang B, et al. mTOR inhibition improves immune function in the elderly. Sci Transl Med. 2014;6(268):268ra179.

[9] Kennedy BK, Lamming DW. The mechanistic target of rapamycin: The grand ConducTOR of metabolism and aging. Cell Metab. 2016;23(6):990-1003.

[10] Lamming DW, Ye L, Katajisto P, Goncalves MD, Saitoh M, Stevens DM, et al. Rapamycin-induced insulin resistance is mediated by mTORC2 loss and uncoupled from longevity. Science. 2012;335(6076):1638-43.

[11] Arriola Apelo SI, Neuman JC, Baar EL, Syed FA, Cummings NE, Brar $\mathrm{HK}$, et al. Alternative rapamycin treatment regimens mitigate the impact of rapamycin on glucose homeostasis and the immune system. Aging Cell. 2016;15(1):28-38.

[12] Bayle JH, Grimley JS, Stankunas K, Gestwicki JE, Wandless TJ, Crabtree GR. Rapamycin analogs with differential binding specificity permit orthogonal control of protein activity. Chem Biol. 2006;13(1):99-107.

[13] MTOR inhibitors [cited Retrieved 16:52, January 10, 2018 Retrieved 16:52, January 10, 2018]. Available from: https:// en.wikipedia.org/w/index.php?title=MTOR_inhibitors\&old id $=816453342$

[14] Sabatini DM. Twenty-five years of mTOR: Uncovering the link from nutrients to growth. Proc Natl Acad Sci U S A. 2017;114(45):11818-25.

[15] Mahoney SJ, Narayan S, Molz L, Berstler LA, Kang SA, Vlasuk GP, et al. A small molecule inhibitor of Rheb selectively targets mTORC1 signaling. Nature Communications. 2018;9(1):548. 